\title{
Effect of iridium loading on the formation of protonic acid sites over Ir/Pt-HZSM5
}

\author{
H.D. Setiabudi ${ }^{1}$, A.A. Jalii ${ }^{1}$, S. Triwahyono ${ }^{2,3,}$, , S.N. Timmiati ${ }^{1}$, N.H.R. Annuar ${ }^{2}$, N.A.A. Fatah ${ }^{1}$, M.R. Sazegar ${ }^{2}$, L.P. Teh ${ }^{2}$ \\ ${ }^{1}$ Institute of Hydrogen Economy, Faculty of Chemical Engineering, Universiti Teknologi Malaysia, 81310 UTM Johor Bahru, Johor, Malaysia \\ ${ }^{2}$ Department of Chemistry, Faculty of Science, Universiti Teknologi Malaysia, 81310 UTM Johor Bahru, Johor, Malaysia \\ ${ }^{3}$ Ibnu Sina Institute for Fundamental Science Studies, Universiti Teknologi Malaysia, 81310 UTM Johor Bahru, Johor, Malaysia \\ Received 12 December 2012, Revised 22 January 2013, Accepted 15 February 2013, Available online 21 February 2013
}

\begin{abstract}
The Ir/Pt-HZSM5 with different iridium loading (0.3-1.0 wt\%) was prepared by impregnation of iridium on Pt-HZSM5. The acidic properties of Ir/PtHZSM5 were studied by FTIR spectroscopy, while the activity of the catalysts was tested for $n$-pentane isomerization in a microcatalytic pulse reactor. The IR results of adsorbed 2,6-lutidine showed that all catalysts possessed strong Brönsted and Lewis acid sites in the outgassing at $473 \mathrm{~K}$ and below. When Ir/Pt-HZSM5 was heated in hydrogen, protonic acid sites were formed with concomitant decrease of Lewis acid sites. An increase in iridium loading continuously decreased the Lewis and Brönsted acid sites and inhibited the formation of protonic acid sites induced by hydrogen. The formation of protonic acid sites induced by hydrogen was also confirmed by the formation of electron detected by ESR spectroscopy. Additionally for $n$-pentane isomerization, an increase in iridium loading decreased the yield of isopentane due to the inhibition in the formation of protonic acid sites via hydrogen spillover phenomenon.
\end{abstract}

| Ir/Pt-HZSM5 | Hydrogen | Protonic acid sites | FTIR adsorbed 2,6-lutidine | $n$-pentane isomerization |

(B) 2013 IbnuSina Institute. All rights reserved. http://dx.doi.org/10.11113/mjfas.v9n1.75

\section{INTRODUCTION}

Bifunctional heterogeneous catalysts, consisting of a noble metal supported on microporous and mesoporous materials have drawn much attention due to their efficiency for the isomerization process and for the synthesis of high octane number [1-3]. Among the available supports, zeolites, crystalline alumino-silicates, have attracted significant attention from numerous researchers due to their thermal stability, strong acidity and high surface area. In particular, platinum supported on HZSM5 zeolite was found to be active and stable for isomerization process [1].

In the recent years, bimetallic heterogeneous catalysts have attracted an increasing interest due to their capability to improve the activity, stability and selectivity of the catalyst. In particular, bimetallic catalysts composed by iridium and platinum were found to be active and stable for isomerization process. Additionally, the introduction of iridium as co-promoter enhanced the catalytic activity of monometallic catalysts and decreased the formation of coke. Yang and Woo [4] reported that bimetallic Pt-Ir/ $\mathrm{NaY}$ maintained better activity towards $n$-heptane reforming reaction than $\mathrm{Pt} / \mathrm{NaY}$ catalyst due to a decrease in the formation of coke. In addition, Aboul-Gheit et al. [5] reported that the combination of iridium on $\mathrm{Pt} / \mathrm{HZSM} 5$ produces a more active catalyst compared to the monometallic Pt/HZSM5. In our previous assignment [6], we have found that the introduction of iridium $(0.1 \mathrm{wt} \%)$ on Pt-HZSM5 increased the selectivity of isopentane and decreased the selectivity of cracking products. The increase in the isopentane product may be caused by an increased in the acidity and active protonic acid sites originating from molecular hydrogen. Whereas, the decrease in the cracking products may be caused by the bonding of iridium to perturbed silanol groups of Pt-HZSM5.

The isomerization of light paraffins such as $n$ pentane, $n$-hexane and $n$-heptane proceeds via hydrogen dissociation on a metal site under a hydrogen atmosphere [1]. The promotive effect of hydrogen has been interpreted by the generation of protonic acid sites via dissociative adsorption of molecular hydrogen on the metal sites to form hydrogen atom, followed by the surface diffusion of the spillover hydrogen to a Lewis acid sites where the hydrogen atoms release an electron to form a proton. Then, the proton is located on the surface oxygen atom near the Lewis acid sites and act as a catalytically active protonic acid site. The generation of protonic acid sites originate from molecule hydrogen has only been observed for a limited class of catalyst, including zeolite supported metal catalysts $[3,6,7,8]$ and zirconia based acid catalysts [9-13.]. However, the mechanism and the rate of the spillover vary with the type of catalyst. For instance, hydrogen adsorption on $\mathrm{Pt} / \mathrm{WO}_{3}-\mathrm{ZrO}_{2}$ is faster than that on $\mathrm{WO}_{3}-\mathrm{ZrO}_{2}$ because of the existence of $\mathrm{Pt}$ sites on $\mathrm{WO}_{3}-\mathrm{ZrO}_{2}$ that could facilitate the spillover of hydrogen atoms [10-11]. A similar phenomenon was observed in $\mathrm{MoO}_{3}$ type catalyst, in which the presence of $\mathrm{Pt}$ is required in the hydrogen adsorption [14].

In this report, we have studied the effect of iridium loading on the acidity and catalytic activity of $\mathrm{Ir} / \mathrm{Pt}-$

*Corresponding author. E-mail: sugeng@utm.my

(S. Triwahyono) Tel:(60)-7-5536076, Fax: (60)-7-5536080 
HZSM5. Based on the IR and ESR studies, an increase in the iridium loading (0.3-1.0 $\mathrm{wt} \%)$ decreased the number of acid sites and the formation of protonic acid sites from molecular hydrogen. Additionally, an increase in iridium loading decreased the activity of catalyst towards $n$-pentane isomerization due to the inhibition in the formation of protonic acid sites via hydrogen spillover phenomenon.

\section{EXPERIMENTAL}

\subsection{Catalyst preparation}

A commercial HZSM5 (Zeolyst International) with $\mathrm{Si} / \mathrm{Al}$ atomic ratio of 23 was used as a catalyst support. Ir/Pt-HZSM5 was prepared according to the method described in previous report [6]. In brief, Pt-HZSM5 was prepared by incipient wetness impregnation of HZSM5 with requisite quantity of $\mathrm{H}_{2} \mathrm{PtCl}_{6} \cdot \mathrm{H}_{2} \mathrm{O}$ (Merck) in aqueous solution to obtain $0.1 \mathrm{wt} \% \mathrm{Pt}$ in the finished catalyst. The prepared Pt-HZSM5 was then impregnated with aqueous solution of $\mathrm{IrCl}_{3} \cdot 3 \mathrm{H}_{2} \mathrm{O}$ (Merck) to obtained bimetallic Ir/PtHZSM5 catalyst, followed by drying at $383 \mathrm{~K}$ overnight and calcination at $823 \mathrm{~K}$ for $3 \mathrm{~h}$ in air. The content of iridium was adjusted to $0.3,0.5$ and $1.0 \mathrm{wt} \%$.

The prepared Ir/Pt-HZSM5 catalyst denoted as 0.3 Ir/Pt-HZSM5, 0.5Ir/Pt-HZSM5 and 1.0Ir/Pt-HZSM5 for $0.3,0.5$ and $1.0 \mathrm{wt} \% \mathrm{Ir}$, respectively. The surface area of 0.3Ir/Pt-HZSM5, 0.5Ir/Pt-HZSM5 and 1.0Ir/Pt-HZSM5 were $460,443,419 \mathrm{~m}^{2} / \mathrm{g}$, respectively.

\subsection{Infrared spectroscopy}

Before the IR analysis, catalysts were activated according to the method described in the literature [13]. In brief, a self-supported wafer placed in an in-situ stainless steel IR cell with $\mathrm{CaF}_{2}$ windows was heated at $673 \mathrm{~K}$ in hydrogen flow for $3 \mathrm{~h}$ and outgassed at $673 \mathrm{k}$ for $3 \mathrm{~h}$. The activated catalyst was exposed to 2 Torr of 2,6-lutidine at room temperature for $30 \mathrm{~min}$, followed by outgassing at room temperature, 373 and $473 \mathrm{~K}$ for $30 \mathrm{~min}$, respectively.

The formation of protonic acid sites from molecular hydrogen was observed according to the method described in the literature [15]. The 2,6-lutidine pre-adsorbed catalyst was exposed to 100 Torr of hydrogen at room temperature. The catalyst was then heated stepwise from room temperature to $473 \mathrm{~K}$ in $50 \mathrm{~K}$ increments.

All spectra were recorded at room temperature by Perkin-Elmer Spectrum GX FT-IR Spectrometer. In order to compare the surface coverage of the adsorbed species between different wafer thicknesses, all spectra were normalized using the overtone and combination vibrations of the MFI between 2100 and $1550 \mathrm{~cm}^{-1}$ after activation.

\subsection{Electron spin resonance}

A JEOL JES-FA100 ESR Spectrometer was used to observe the formation of electron holes or unpaired electrons in vacuo heating, and to observe the interaction of the electron holes or unpaired electrons with electrons formed from molecular hydrogen at room temperature to $473 \mathrm{~K}$. The catalyst was outgassed at $673 \mathrm{~K}$ for $3 \mathrm{~h}$ followed by the introduction of 50 Torr of hydrogen at room temperature. The catalyst was then heated stepwise from room temperature to $473 \mathrm{~K}$ in $50 \mathrm{~K}$ increments [7].

\subsection{Isomerization of $n$-pentane}

The isomerization of $n$-pentane was performed under hydrogen atmosphere in a microcatalytic pulse reactor according to the method described in the literature [6]. Prior to the reaction, $0.2 \mathrm{~g}$ of catalyst was treated in a flow of oxygen $\left(\mathrm{F}_{\text {Oxygen }}=100 \mathrm{ml} / \mathrm{min}\right)$ for $1 \mathrm{hr}$, followed by hydrogen $\left(\mathrm{F}_{\text {Hydrogen }}=100 \mathrm{ml} / \mathrm{min}\right)$ for $3 \mathrm{hr}$ at $673 \mathrm{~K}$ and cooled down to $548 \mathrm{~K}$ in a hydrogen stream. A dose of $n$ pentane $(43 \mu \mathrm{mol})$ was injected over the activated catalyst, and the products were trapped at $77 \mathrm{~K}$ before flashevaporation into an online $6090 \mathrm{~N}$ Agilent gas chromatograph equipped with HP-5 Capillary Column and FID detector. The intervals between each pulse injection were kept constant at $20 \mathrm{~min}$.

The rate of $n$-pentane conversion $\left(r_{n \text {-pentane }}\right)$ was calculated according to Eq. (1)

$r_{n-\text { pentane }}=k \frac{\sum[\mathrm{C}]_{i}}{\sum[\mathrm{C}]_{i}+[\mathrm{C}]_{\text {residual } n \text {-pentane }}}$

where $[\mathrm{C}]_{i}$ and $[\mathrm{C}]_{\text {residual } n \text {-pentane }}$ represented mol number for particular product and for residual $n$-pentane which is calculating based on the Scott hydrocarbon calibration standard gas (Air Liquide America Specialty Gases LLC). The rate constant $(k)$ was determined by the molar concentration of $n$-pentane divided by the surface area of the catalyst per unit time, with the assumption that the retention time for reactant in the catalyst bed was negligibly small. The calculated $k$ values of $n$-pentane isomerization over 0.3Ir/Pt-HZSM5, 0.5Ir/Pt-HZSM5 and 1.0Ir/PtHZSM5 were $0.47,0.49$ and $0.52 \mu \mathrm{mol} /\left(\mathrm{s} \cdot \mathrm{m}^{2} \cdot\right.$ cat $)$, respectively.

The selectivity $\left(S_{i}\right)$ and yield $\left(Y_{i}\right)$ to particular compound was calculated according to Eq. (2) and (3), respectively.

$S_{i}=\frac{[\mathrm{C}]_{i}}{\sum[\mathrm{C}]_{i}} \times 100$

$Y_{i}=\frac{\sum[\mathrm{C}]_{i}}{\sum[\mathrm{C}]_{i}+[\mathrm{C}]_{\text {residual } n \text {-pentane }}} \times S_{i}$ 


\section{RESULTS \& DISCUSSION}

The acid sites in the $0.3 \mathrm{Ir} / \mathrm{Pt}$-HZSM5, $0.5 \mathrm{Ir} / \mathrm{Pt}-$ HZSM5 and 1.0Ir/Pt-HZSM5 was qualitatively probed by 2,6-lutidine adsorption monitored by IR spectroscopy. Fig. 1 shows the IR spectra of 2,6-lutidine adsorbed on activated $0.3 \mathrm{Ir} / \mathrm{Pt}-\mathrm{HZSM} 5$ (A), $0.5 \mathrm{Ir} / \mathrm{Pt}-\mathrm{HZSM} 5$ (B) and $1.0 \mathrm{Ir} / \mathrm{Pt}-$ HZSM5 (C) in the region of $1750-1350 \mathrm{~cm}^{-1}$ as a function of outgassing temperature. The 2,6-lutidine pre-adsorbed catalysts were outgassed at room temperature, $373 \mathrm{~K}$ and $473 \mathrm{~K}$. All the catalysts showed the absorbance bands at $1700,1680,1650$ and $1640 \mathrm{~cm}^{-1}$, which are associated with the 2,6-lutidinium cations adsorbed on Brönsted acid sites [16]. The absorbance bands at 1605, 1585, 1490, 1460, 1410 and $1385 \mathrm{~cm}^{-1}$ are assigned to the Lewis acid sites [16].

For all catalysts, 2,6-lutidine probe molecules were able to interact strongly with acidic sites at room temperature and were retained at the outgassing temperature of $473 \mathrm{~K}$. In general, if the outgassing temperature is raised, 2,6-lutidine molecules adsorbed on weak acid sites should desorbed at lower temperatures, and those adsorbed on strong acid sites should be desorbed at higher temperatures. For all catalysts, the intensity of the absorbance bands assigned to Lewis acid sites decreased significantly with outgassing temperature indicating wide distribution of Lewis acid sites. However, the intensity of the absorbance bands assigned to Brönsted acid sites increased significantly with outgassing temperature. The increase in the absorbance bands ascribed to the Brönsted acid sites at higher outgassing temperatures may be related to the steric shielding of the methyl group in which the removal of 2,6lutidine adsorbed on the Lewis acid sites allows the lutidinium cations to access relatively weaker protonic acid sites inside the zeolite bulk. The significant changes in the intensity of the absorbance bands with outgassing temperature indicating that all of the catalysts possessed a considerable number of relatively weak and medium acid sites as well as strong acid sites. Even though all catalysts exhibited similar phenomenon, it is obvious that the number of acid sites is higher for 0.3Ir/Pt-HZSM5 catalysts, followed by 0.5 and $1.0 \mathrm{wt} \%$.

The effect of iridium loading on the acidity of Ir/PtHZSM5 are more clearly illustrated in Fig. 1(D), in which the absorbance of the IR bands at Brönsted acid sites (1640 $\left.\mathrm{cm}^{-1}\right)$ and Lewis acid sites $\left(1585 \mathrm{~cm}^{-1}\right)$ observed at the outgassing temperature of $473 \mathrm{~K}$ were plotted as a function of iridium loading. A slight decreased in the Brönsted and Lewis acid sites were observed with increasing iridium content from 0.3 to $1.0 \mathrm{wt} \%$ which may be related to the presence of bulk iridium oxide on the external surface of the catalyst which may hinder the accessibility of acidic sites to the 2,6-lutidine probe molecule. Partial coverage of the acid sites was also observed on Ir/HZSM5 and Ir-Mo/HZSM5 catalysts reported by Aboul-Gheit and co-worker. [17-18]. The addition of $0.35 \mathrm{wt} \%$ iridium on HZSM5 and $0.5 \mathrm{wt} \%$ iridium on Mo/HZSM5 resulted to a decrease in all species of acid sites due to the coverage of a portion of the acid sites with iridium species. In addition, this phenomenon was also observed on palladium and/or platinum loaded on $\mathrm{H}$ Beta reported by de Lucas et al. [19]. They suggested that a slight decrease in the strong acid density of monometallic catalysts with increasing metal content, mainly on platinum samples, was due to the acid sites to be partially covered by metal particles.

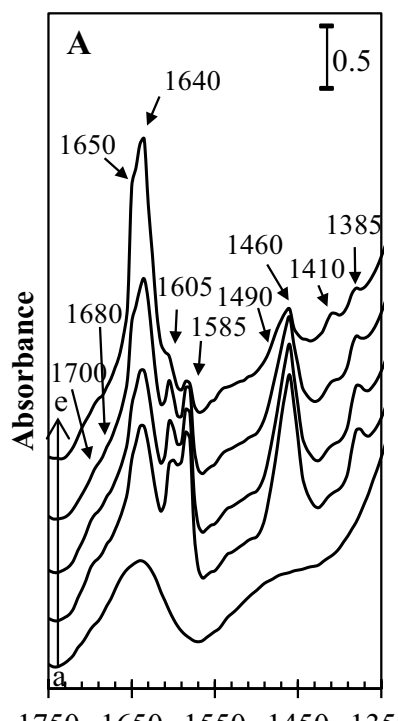

$\begin{array}{lllll}1750 & 1650 & 1550 & 1450 & 1350\end{array}$

Wavenumber $\left[\mathrm{cm}^{-1}\right]$

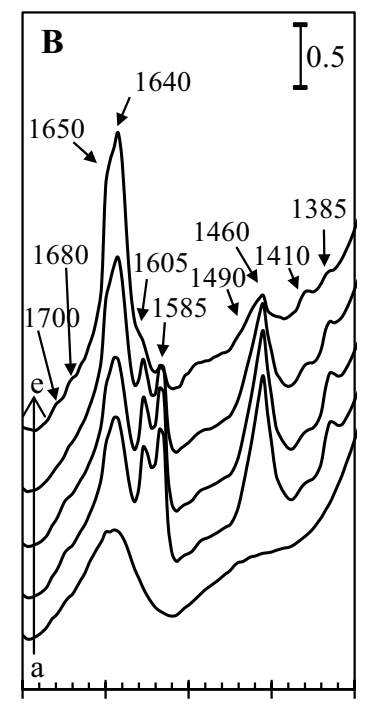

Wavenumber $\left[\mathrm{cm}^{-1}\right]$

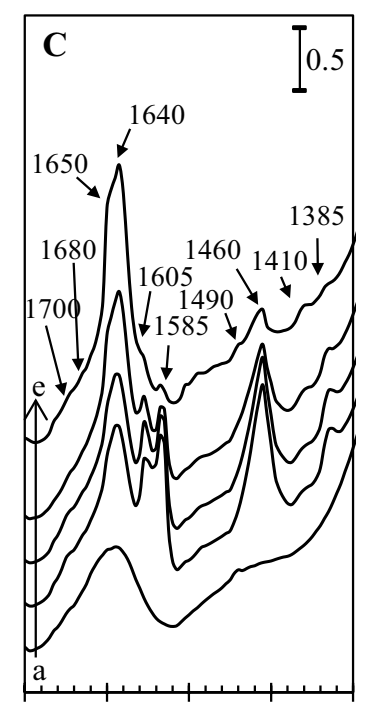

$\begin{array}{lllll}1750 & 1650 & 1550 & 1450 & 1350\end{array}$

Wavenumber $\left[\mathrm{cm}^{-1}\right]$

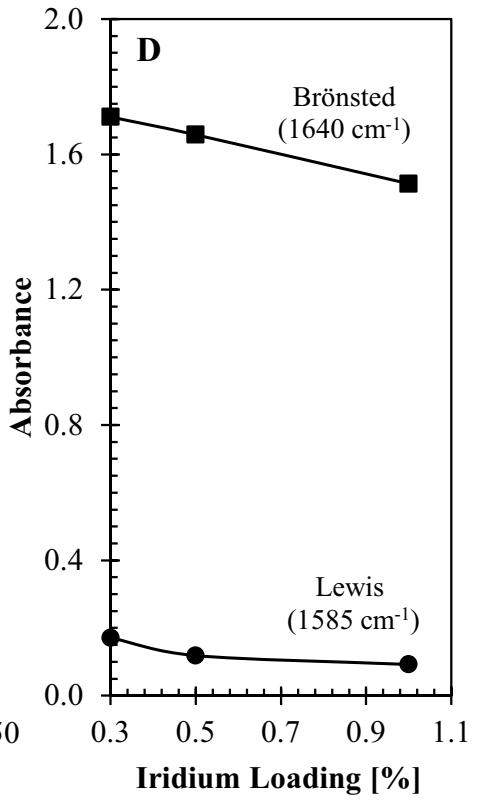

Fig. 1. IR spectra of 2,6-lutidine adsorbed on activated (A) $0.3 \mathrm{lr} / \mathrm{Pt}-\mathrm{HZSM} 5$, (B) $0.5 \mathrm{Ir} / \mathrm{Pt}-\mathrm{HZSM} 5$ and (C) $1.0 \mathrm{lr} / \mathrm{Pt}-\mathrm{HZSM} 5$ catalysts at (b) room temperature, followed by heating in a vacuum at (c) room temperature, (d) $373 \mathrm{~K}$, (e) $473 \mathrm{~K}$. (a) before exposure of 2,6-lutidine. (D) Variations in the absorbance of the IR bands for Brönsted and Lewis acid sites after removal of 2,6-lutidine at $473 \mathrm{~K}$. 
Fig. 2 shows the changes in the IR spectra when the 2,6-lutidine preadsorbed activated 0.3Ir/Pt-HZSM5 (A), 0.5Ir/Pt-HZSM5 (B) and 1.0Ir/Pt-HZSM5 (C) were heated from room temperature to $473 \mathrm{~K}$ in the presence of 100 Torr of hydrogen. Since the 2,6-lutidine preadsorbed sample was outgassed at $473 \mathrm{~K}$, the acid sites under consideration are only strong acid sites that can retain 2,6-lutidine at the outgassing temperature of $473 \mathrm{~K}$ and below. As the temperature of hydrogen was increased, the intensity of the bands at $1605,1585,1460$ and $1385 \mathrm{~cm}^{-1}$ corresponding to the Lewis acid sites decreased with a concomitant increase in the intensity of the bands at 1700,1680,1650, and 1640 $\mathrm{cm}^{-1}$, which are attributed to the peaks of 2,6-lutidine on Brönsted acid sites. Based on the concept of 'molecular hydrogen-originated protonic acid sites', hydrogen molecules are dissociatively adsorbed on specific sites to form hydrogen atoms, followed by the release of electrons near to the cus metal cations forming protonic acid sites. Then, the electrons stabilized the cus metal cation as long as the 2,6-lutidine was protonated and interacted with extralattice or basic oxygen. All catalysts have the ability to interchange the acidic characters of the Lewis and protonic acid sites when they are heated in the presence of molecular hydrogen.

Fig. 2(D) shows the variation in the number of protonic acid sites formed as a function of temperature for 0.3Ir/Pt-HZSM5, 0.5Ir/Pt-HZSM5 and 1.0Ir/Pt-HZSM5. For all catalysts, an increase in the heating temperature increased the number of protonic acid sites formed, whereas an increase in the amount of iridium loading gradually decreased the ability of catalyst to form protonic acid sites from molecular hydrogen. These results may be due to the decrease in the number of strong Lewis acid sites, as evidenced by IR spectra of 2,6-lutidine adsorption. Although some differences were observed, the effect of hydrogen is essentially the same as that observed for $\mathrm{Pt} / \mathrm{HZSM} 5$ [6], $\mathrm{Zn} / \mathrm{HZSM} 5$ [20], $\mathrm{Pt} / \mathrm{WO}_{3}-\mathrm{ZrO}_{2}$ [11] and $\mathrm{MoO}_{3}-\mathrm{ZrO}_{2}[15]$ catalysts.

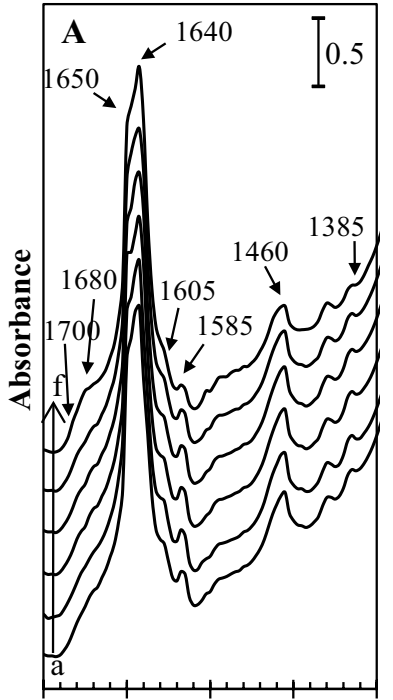

$\begin{array}{lllll}1750 & 1650 & 1550 & 1450 & 1350\end{array}$

Wavenumber $\left[\mathrm{cm}^{-1}\right]$

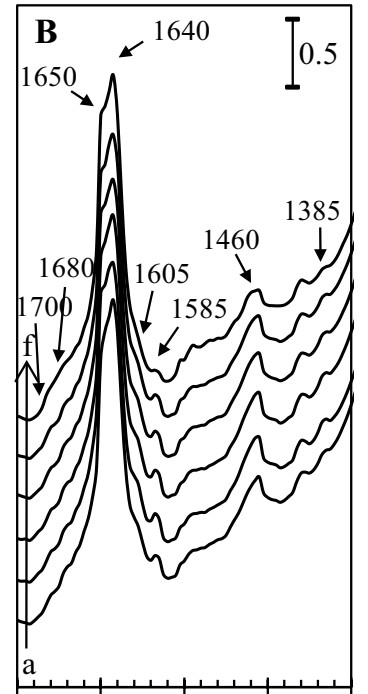

$\begin{array}{lllll}1750 & 1650 & 1550 & 1450 & 1350\end{array}$

Wavenumber $\left[\mathrm{cm}^{-1}\right]$

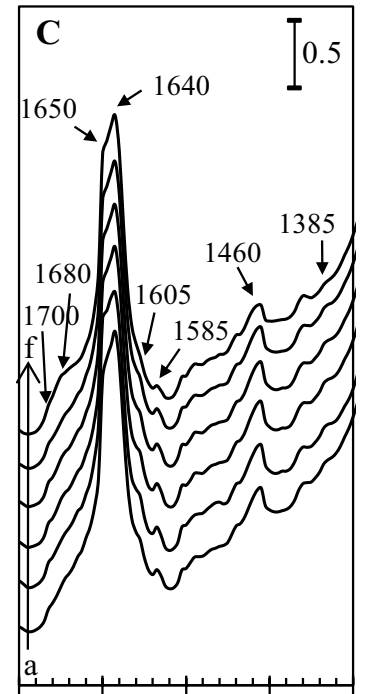

$\begin{array}{lllll}1750 & 1650 & 1550 & 1450 & 1350\end{array}$

Wavenumber $\left[\mathrm{cm}^{-1}\right]$

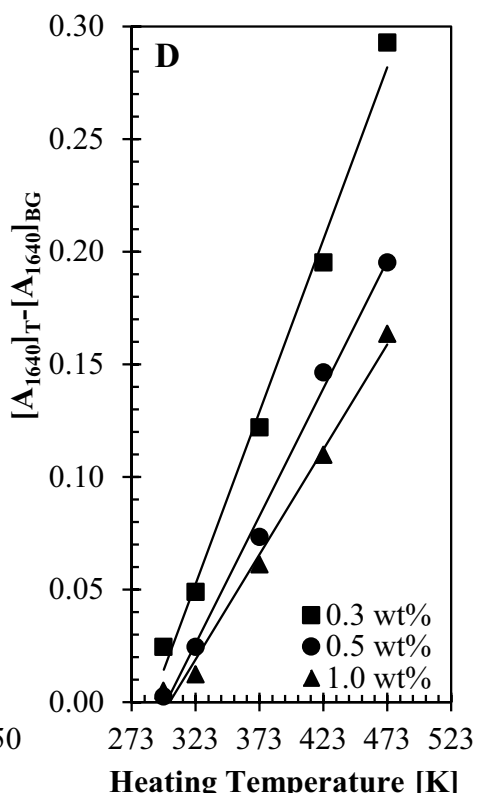

Heating Temperature [K]

Fig. 2. Spectral changes when 2,6-lutidine preadsorbed (A) $0.3 \mathrm{Ir} / \mathrm{Pt}-\mathrm{HZSM} 5$, (B) $0.5 \mathrm{Ir} / \mathrm{Pt}-\mathrm{HZSM} 5$ and (C) $1.0 \mathrm{lr} / \mathrm{Pt}-\mathrm{HZSM} 5$ catalysts were heated in hydrogen at (b) $298 \mathrm{~K}$, (c) $323 \mathrm{~K}$, (d) $373 \mathrm{~K}$, (e) $423 \mathrm{~K}$ and (f) $473 \mathrm{~K}$. (a) before exposure to hydrogen. (D) Variation of the change of absorbance at $1640 \mathrm{~cm}^{-1}$ with heating in hydrogen for different catalysts. $\left[A_{1640}\right]_{B G}$ represents the intensity of the Brönsted acid sites before hydrogen adsorption.

Fig. 3 shows the ESR signals of $0.3 \mathrm{Ir} / \mathrm{Pt}-\mathrm{HZSM} 5$ (A), 0.5Ir/Pt-HZSM5 (B) and 1.0Ir/Pt-HZSM5 (C), when the catalysts were outgassed at $673 \mathrm{~K}$ for $3 \mathrm{~h}$, followed by heating in the presence of hydrogen at different temperatures. As the catalysts were outgassed at $673 \mathrm{~K}$ for 3 $\mathrm{h}$, the intensity of the ESR signal at $\mathrm{g}=1.99$ increased. This may be due to the desorption of hydroxyl groups from the surface of the catalysts, which subsequently leave the electron-deficient metal cations. The introduction of gaseous hydrogen, followed by heating, resulted in the formation of electrons and protonic acid sites where the electrons were trapped in the electron-deficient metal cations, resulting the reduction of the ESR signal at $\mathrm{g}=1.99$. Although all the catalysts exhibited a similar phenomenon, $0.3 \mathrm{Ir} / \mathrm{Pt}$-HZSM5 showed largest changes in the intensity of the signal indicating that the formation of electrons via the hydrogen spillover mechanism is much easier for $0.3 \mathrm{Ir} / \mathrm{Pt}$ HZSM5, compared to that of $0.5 \mathrm{Ir} / \mathrm{Pt}-\mathrm{HZSM} 5$ and $1.0 \mathrm{Ir} / \mathrm{Pt}$ HZSM5 catalyst. The formation of electrons for $0.3 \mathrm{Ir} / \mathrm{Pt}$ HZSM5, 0.5Ir/Pt-HZSM5 and 1.0Ir/Pt-HZSM5 catalysts is more clearly illustrated in Fig. 3(D), in which the variations in the relative intensity of the ESR signal at $\mathrm{g}=1.99$ for all catalysts was plotted as a function of the heating temperature. As the heating temperature was increased, the 
variation in the relative intensity of the ESR signal at $\mathrm{g}=1.99$ decreased, due to the formation of electrons via the hydrogen spillover mechanism. Even though all catalysts exhibited a similar phenomenon, it is obvious that the generation of electrons is higher for $0.3 \mathrm{Ir} / \mathrm{Pt}-\mathrm{HZSM} 5$ catalysts, followed by 0.5 and $1.0 \mathrm{wt} \%$. The results of the ESR study are consistent with the FTIR study of hydrogen adsorption on 2,6-lutidine pre-adsorbed catalysts, in which an increase in iridium loading decreased the formation of protonic acid sites and electrons. The effect of hydrogen on the ESR signal is similar to the results observed for $\mathrm{Pt} / \mathrm{HY}$ catalyst reported by Aziz et al. [7], in which heating the catalyst in the presence of hydrogen partially eliminated the ESR signal related to the trapped electrons or unpair electron at $\mathrm{g}=1.9866$, because of the formation of electron via hydrogen spillover mechanism.
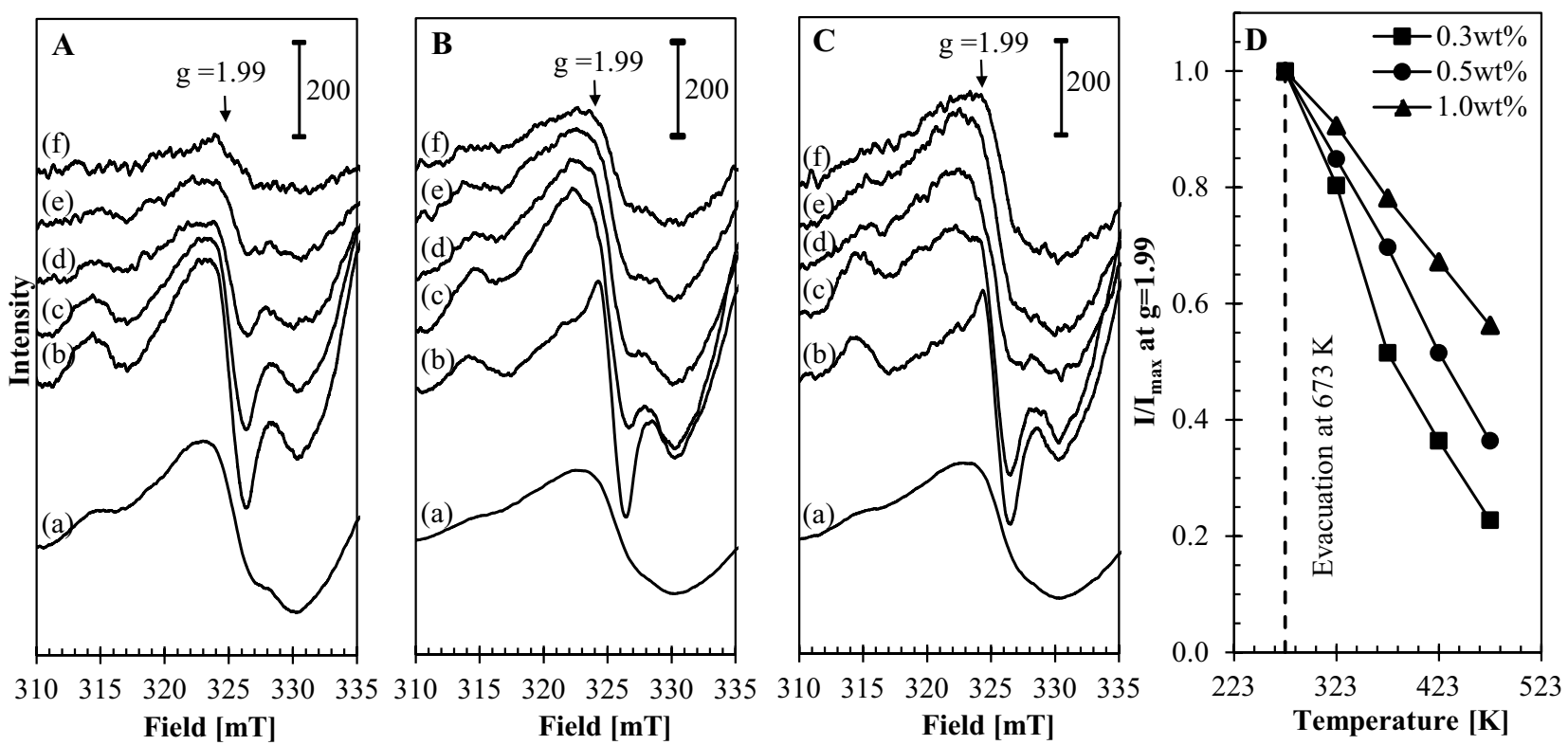

Fig. 3. ESR signal of (A) 0.31r/Pt-HZSM5, (B) 0.51r/Pt-HZSM5 and (C) 1.01r/Pt-HZSM5.(a) Before outgassing at $673 \mathrm{~K}$; (b) after outgassing at $673 \mathrm{~K}$ and heated in the presence of 50 Torr hydrogen at (c) $323 \mathrm{~K}$, (d) $373 \mathrm{~K}$, (e) $423 \mathrm{~K}$, and (f) $473 \mathrm{~K}$. (D) Relative intensity of the ESR signal at $\mathrm{g}=1.99$ as a function of heating temperature.

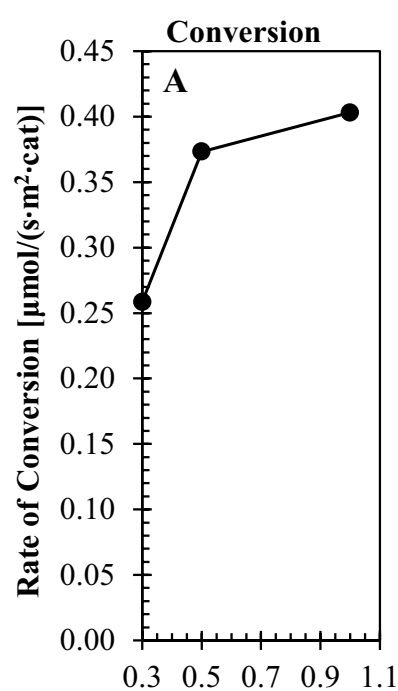

Iridium Loading [\%]

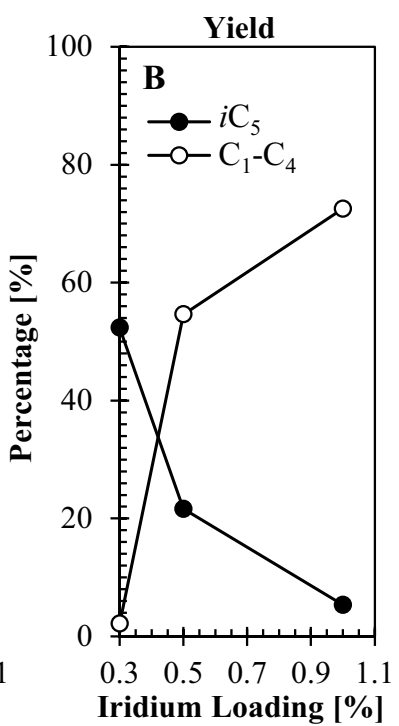

Fig. 4. Effect of iridium loading on the $(A)$ rate of conversion, $(B)$ yield of isopentane and yield of cracking products.

Fig. 4 shows the effect of iridium loading on the rate of conversion, yield of isopentane and yield of cracking products. An increase in iridium loading (0.3-1.0 wt \%) has changed the yield of isopentane and $\mathrm{C}_{1}-\mathrm{C}_{4}$ cracking products in which the isopentane product decreased from $52.4 \%$ to $5.3 \%$ and $\mathrm{C}_{1}-\mathrm{C}_{4}$ cracking products increased from $2.2 \%$ to $72.5 \%$. In addition, the rate of conversion increased from $0.26 \mu \mathrm{mol} /\left(\mathrm{s} \cdot \mathrm{m}^{2} \cdot \mathrm{cat}\right)$ to 0.36 $\mu \mathrm{mol} /\left(\mathrm{s} \cdot \mathrm{m}^{2} \cdot \mathrm{cat}\right)$. In general, the yield of isopentane decreased with iridium loading, while the conversion of $n$ pentane increased, due to the increase in cracking products. Moreover, a decrease in the yield of isopentane with iridium loading was due to the inhibition in the formation of protonic acid sites via hydrogen spillover phenomenon.

\section{CONCLUSION}

The IR results of adsorbed 2,6-lutidine showed that 0.3Ir/Pt-HZSM5， 0.5Ir/Pt-HZSM5 and 1.0Ir/Pt-HZSM5 possessed a considerable number of relatively weak and medium acid sites as well as strong acid sites which can retained the 2,6-lutidine at the outgassing temperature of $473 \mathrm{~K}$. However, an increase in iridium loading resulted to a slight decreased in the Brönsted and Lewis acid sites due 
to the presence of bulk iridium oxide on the external surface of the catalyst.

IR and ESR studies showed that $0.3 \mathrm{Ir} / \mathrm{Pt}-\mathrm{HZSM}$, $0.5 \mathrm{Ir} / \mathrm{Pt}-\mathrm{HZSM} 5$ and $1.0 \mathrm{Ir} / \mathrm{Pt}-\mathrm{HZSM} 5$ catalysts have the ability to form protonic acid sites from molecular hydrogen when they are heated in the presence of molecular hydrogen. However, an increase in the amount of iridium loading gradually decreased the ability of catalyst to form protonic acid sites from molecular hydrogen.

Additionally, an increase in iridium loading decreased the formation of isopentane products for $n$ pentane isomerization due to the inhibition in the formation of protonic acid sites via hydrogen spillover phenomenon.

\section{ACKNOWLEDGEMENT}

This work was supported by The Ministry of Higher Education Malaysia through FRGS Research Grant No. 4L023. Our gratitude also goes to the Hitachi Scholarship Foundation for the Gas Chromatography Instrument Grant.

\section{REFERENCES}

[1] K. Fujimoto, K. Maeda and K. Aimoto, Appl. Catal. A: Gen., 91 (1992), 81-86.

[2] P. Cañizares, A. de Lucas, J.L. Valverde, and F. Dorado, Ind. Eng. Chem. Res., 36 (1997), 4797-4808.

[3] S. Triwahyono, A.A. Jalil, and M. Musthofa, Appl. Catal. A: Gen., 372 (2010), 90-93.

[4] O.B. Yang, S.I. Woo, in: L. Guczi, F. Solymosi, and P. Tetenyi (Eds.), New Frontiers in Catalysis, Proc. 10th Int. Cong. Catal.,
Budapest, Hungary, 19-24 July 1992, Elsevier Science Publishers B.V., Amsterdam, 1993, p. 671-680.

[5] A.K. Aboul-Gheit, A.E. Awadallah, N.A.K. Aboul-Gheit, E.S.A. Solyman, and M.A. Abdel-Aaty, Appl. Catal. A: Gen., 334 (2008), 304-310.

[6] H.D. Setiabudi, A.A. Jalil, S. Triwahyono, N.H.N. Kamarudin, and R.R. Mukti, Appl. Catal. A: Gen., 417-418 (2012), 190-199.

[7] M.A.A. Aziz, N.H.N. Kamarudin, H.D. Setiabudi, H. Hamdan, A.A. Jalil, and S. Triwahyono, J. Nat. Gas Chem., 21 (2012), 29-36.

[8] H.D. Setiabudi, A.A. Jalil, and S. Triwahyono, J. Catal., 294 (2012), 128-135.

[9] S. Triwahyono, T. Yamada, and H. Hattori, Appl. Catal. A: Gen., 250 (2003), 75-81.

[10] S. Triwahyono, T. Yamada, and H. Hattori, Appl. Catal. A: Gen., 242 (2003), 101-109.

[11] S. Triwahyono, A.A. Jalil, and H. Hattori, J. Nat. Gas Chem., 16 (2007), 252-257.

[12] S. Triwahyono, T. Yamada, and H. Hattori, Catal.Lett., 85 (2003), 109-115.

[13] S. Triwahyono, Z. Abdullah, and A.A. Jalil, J. Nat. Gas Chem. 15 (2006), 247-252.

[14] S. Triwahyono, A.A. Jalil, S.N. Timmiati, N.N. Ruslan, and H. Hattori, Appl. Catal. A: Gen., 372 (2010), 103-107.

[15] N.N. Ruslan, N.A. Fadzlillah, A.H. Karim, A.A. Jalil, and S. Triwahyono, Appl. Catal. A: Gen., 406 (2011), 102-112.

[16] C. Morterra, G. Cerrato, and G. Meligrana, Langmuir, 17 (2001), 7053.

[17] A.K. Aboul-Gheit, S.M. Aboul-Fotouh, and N.A.K. Aboul-Gheit, Appl. Catal. A: Gen,.283 (2005), 157.

[18] A.K. Aboul-Gheit, A.E. Awadallah, S.M. El-Kossy, and A.L.H. Mahmoud, J. Nat. Gas Chem., 17 (2008), 337.

[19] A. de Lucas, P. Sánchez, F. Dorado, M.J. Ramos, and J.L. Valverde, Appl. Catal. A: Gen., 294 (2005), 215.

[20] S. Triwahyono, A.A. Jalil, R.R. Mukti, M. Musthofa, N.A.M. Razali, and M.A.A. Aziz, Appl. Catal. A: Gen., 407 (2011) 91. 